\title{
Critical Factors in Financing and Management of Light Rail Transit Systems: Delphi Methodology Approach
}

\author{
Julián Sastre González ${ }^{1}$ and Clara Zamorano Martín ${ }^{2}$ \\ 1. Royal School of Engineering, University of Seville, Sevilla 41007, Spain \\ 2. Civil Engineering Department, Foundation Caminos de Hierro, Madrid 28002, Spain
}

\begin{abstract}
In recent years, a large number of LRT (light rail transit) networks and tramways have been built in Spain using the tender system. The rhythm of construction has been such that very few analyses have been carried out and those that have were only partially done because the main participants involved had ulterior motives which impeded their having a critical and independent opinion of the projects carried out. Within this framework, the Delphi methodology presents itself as a very useful instrument, as the intrinsic advantages that it has added to the characteristic that the experts who participate in the project can remain anonymous without detracting value from the conclusions obtained as these are grouped together according to their worth.
\end{abstract}

Key words: Public-private partnership financing, Delphi, public transport, LRT, management, concessions.

\section{Introduction}

Congestion in cities and new ways of tackling mobility issues, principally on the part of the citizens themselves, are making different public bodies aware that it is worth favoring the development of urban rail network systems and metros, specifically LRT (light rail transit) ${ }^{1}$ and reserved platform systems. Since the construction of the first modern tramway, put into service in Spain in 1994, ten more tramway systems or light rail networks have been built, and at the current time, there are more than 20 under study or in construction. These figures can be extrapolated to Europe as a whole, where there are currently the region of 200 tramway networks of which the majority are located in the 15 member states which made up the European Union on the May 1, 2004. The development expectations of this system and secular financing on the part of the Public Administrations make us think of

Corresponding author: Julian Sastre González, Dr., M.Sc., Ph.D., research fields: public-private partnership, railways, transport planning and sustainable mobility. E-mail: juliansastre@juliansastre.com.

${ }^{1}$ In this paper, LRT or LR and tramways (we refer to modern tramways networks) are used in the same sense as in Spain that has been decided for each case for political/marketing reasons [1]. major development of these systems using the BOT (built, operate and transfer) method. For these systems to run in more efficiently, it would appear obvious to take into account critical factors regarding their financing. The pace of development with which this system has expanded, as regards light rail networks, and the lack of, in some cases voluntary, spreading of information about these, means that the same mistakes are being repeated systematically from one project to another. A recent study carried out in Spain [2], allowed for the compilation of extensive information on 22 Spanish case-studies [3, 4], as well as others from different parts of Europe, analyzing variables of supply, demand and cost to which was added a detailed study on nine projects following a laborious interviewing process. As can be seen in Table 1, 90\% of these had problems during the construction and operational phases, amongst which unforeseen events during construction stands out, There are also other factors to be taken into account, such as an increase in investment cost, as can be observed in Fig. 1, which affected a large number of the projects. Over-costing in the operational phase is the problem which has the least effect on infrastructures as a whole, perhaps in part 
Table 1 Comparative analysis of the solutions of underground or overland metro.

\begin{tabular}{|c|c|}
\hline \multicolumn{2}{|l|}{ Comparative analysis of solutions for underground or overland metro systems } \\
\hline \multicolumn{2}{|l|}{ Underground metro system } \\
\hline Advantages & Other remarks \\
\hline $\begin{array}{l}\text { Does not interfere with the road network nor reduce its capacity } \\
\text { Does not affect traffic } \\
\text { Greater commercial speed } \\
\text { Less impact on surface building work except when problems involving } \\
\text { subsidence or archaeological difficulties occur } \\
\text { Increased capacity } \\
\text { Increased road safety } \\
\text { Improved initial image which helps social support }\end{array}$ & $\begin{array}{l}\text { Total times for each mode of transport can be } \\
\text { greater or lesser depending on each case and } \\
\text { require, just as demand assessment does, specific } \\
\text { studies }\end{array}$ \\
\hline \multicolumn{2}{|l|}{ Overland metro } \\
\hline Advantages & Other remarks \\
\hline $\begin{array}{l}\text { Increased accessibility } \\
\text { Possibility of more stops } \\
\text { Notably cheaper to build and operate } \\
\text { Greater acceptance on the part of users in terms of comfort sensation as they } \\
\text { can enjoy the local environment whilst travelling without producing the feeling } \\
\text { of claustrophobia } \\
\text { Facilitates the implantation of restrictive measures for private traffic to relieve } \\
\text { congestion in the city centre } \\
\text { Shorter building work duration in theory (although obtaining residence permits } \\
\text { in public spaces may cause troublesome delays) } \\
\text { Easier to spread } \\
\text { Greater security against terrorist attacks and emergencies (security) }\end{array}$ & $\begin{array}{l}\text { On visual or aesthetic impact is also debatable. } \\
\text { Overland systems, at the moment, use catenaries } \\
\text { (although it must be mentioned that the recent } \\
\text { Bordeaux overland did not use overhead cabling) } \\
\text { though often are carried out providing a complete } \\
\text { urbanisation of the environment, from "façade to } \\
\text { façade" and "giving back the city" or improving } \\
\text { some areas of this }\end{array}$ \\
\hline
\end{tabular}

Source: In-house based on diverse interviews.

because they had only recently been put into service.

A highly advisable way of using past experiences to the benefit of the construction of new projects is via the use of perspective, specifically by the application of the Delphi method [5].

The Delphi method is included in those techniques known as "expert methods" which, unlike the extrapolative or correlation methods, require specific data on past experiences, based on consulting people who have vast knowledge on the subject in hand. This method is usually used when one of the following conditions occurs:

(1) There is no historical data with which to work. A typical case in this situation is the provision of new technologies. One must take into account that the projects in place on the Iberian Peninsula have all been recently completed;

(2) The impact of external factors has a greater influence in the evolution than the internal ones. In this way, the appearance of favourable regulatory legislation (this is the case in Spain with the concessions on Infrastructures Law of 2003 and the Regulations of Public Service Contracting of 2007), and the support on the part of some agents toward certain technologies or systems can cause major development in these areas when, without which, it would have occurred at a much slower pace;

(3) The ethical, moral, social and political conditions dominate over the economical and technological ones in an evolutionary process. In this case, one type of technology can see its development hindered if the technology itself is rejected by society, or stimulated by political acceptance as in seen in the case of the light rail networks. They are, also, urban projects of major political impact.

The aim that has been achieved by the application of the Delphi method is to establish the key factors for financing a new tramway or light-rail network based on the opinion of qualified specialists [6]. 


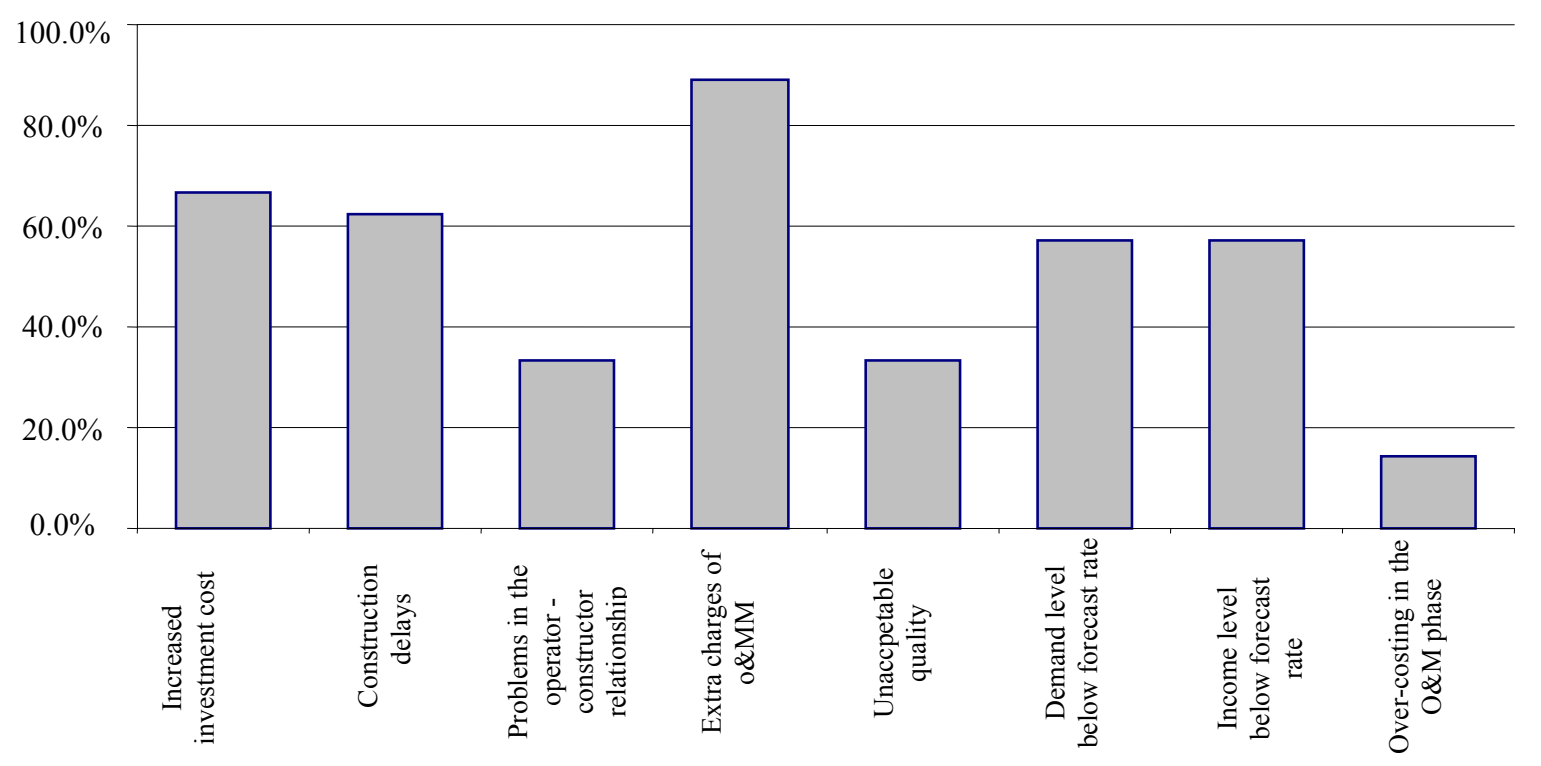

Fig. 1 Main problems encountered.

\section{Methodology}

The methodology has been carried out in two stages. The first, qualitative, in which experts were requested to provide their reasoning with respect to the opinions presented and later quantitative analysis was carried out in which the experts were asked to answer survey about the main parameters.

The first stage was performed by the use of personal interview which lasted for around $2 \mathrm{~h}$ and were held over 22 months depending on when the experts were available.

The second stage was done by sending a survey containing the parameters by e-mail, and through this system the results were returned in a period of about two weeks.

For preparation of the first stage, a basic questionnaire was designed based around the sector's main issues and added to the results obtained from the analysis of twenty-two case studies from Sastre's 2009 study [7], as mentioned beforehand.

The second step was the selection of the expert panel. The basis of the idea was to get opinions from a wide spectrum of specialists, who responded to the group of agents involved in this type of project. A basic requirement was that they had had a high level of authentic responsibility in several projects of the type under study. Fifteen specialists from Spain and Portugal have taken part, and these can be grouped into four categories:

- 7 heads of public departments;

- 3 from the financial sector;

- 3 concessionary partners;

- 2 sector researchers.

After carrying out the interview analysis, the a priori conclusions were established and the questionnaire was designed which would be the basis for the second phase of the study. The results of both phases allow to extract the research's findings.

The practical way of applying the method has been set out in Fig. 2.

\section{Phase I: Qualitative \\ Considerations-Lessons Learnt}

The points of interest which are obtained from the first phase analysis of the study are the following: 


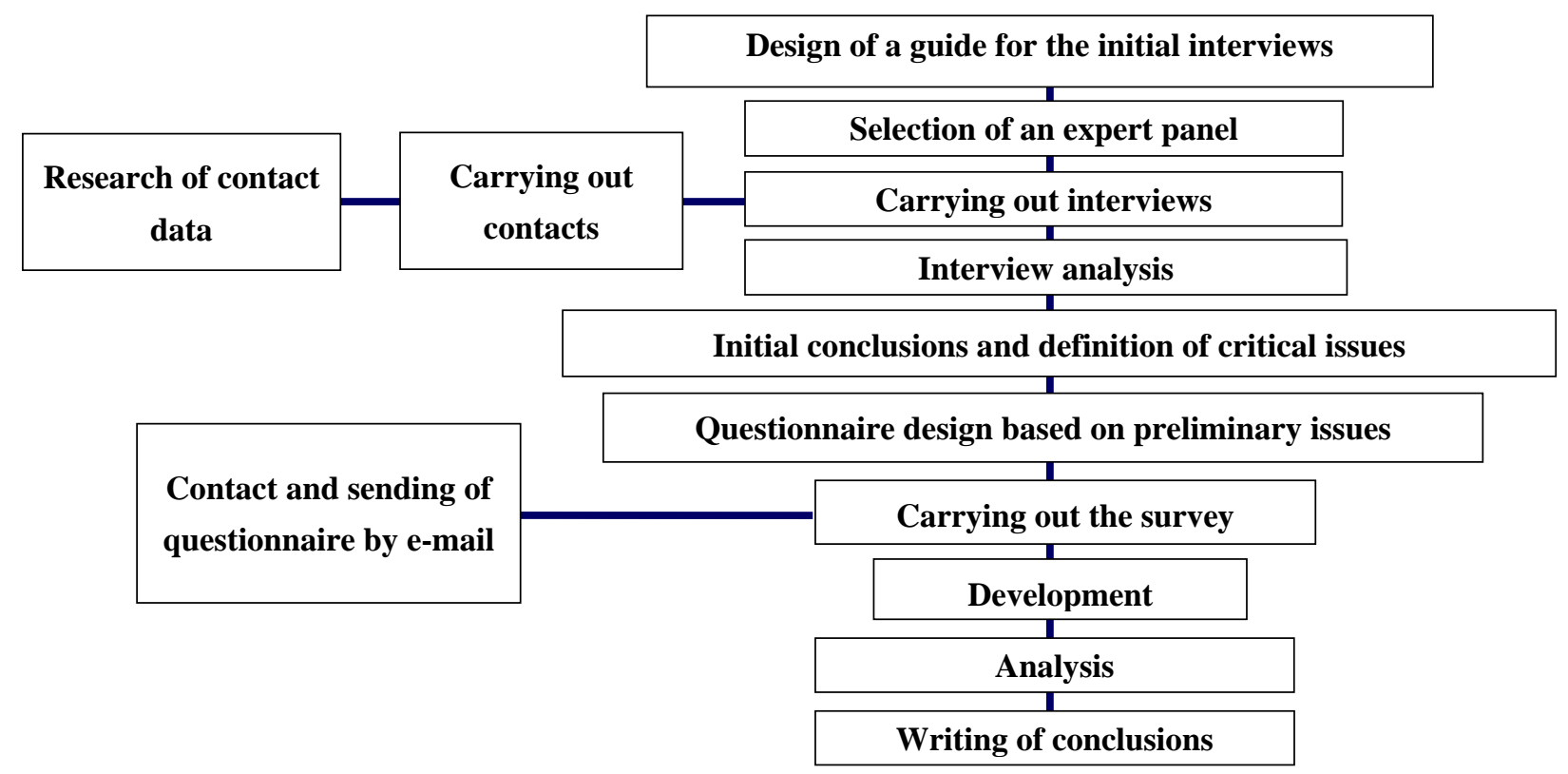

Fig. 2 Applied Delphi method.

Source: In-house.

\subsection{Interest Caused by Light Rail Networks}

From the point of view of its contribution as a transport system, the utility of light rail networks are centred on two scenarios:

As a main means of transport in medium-sized cities of 300,000 to 500,000 inhabitants where the urban infrastructure allows for this and transport is carried out largely overland. The minimum suggested level is 2,000 passengers per kilometre of track and a maximum of 5,000 passengers per hour in each direction.

In larger cities, acting as a complement to the conventional metropolitan system.

The light rail network is characterised by greater accessibility [7] than a conventional underground metro, this means greater acceptance on the part of senior citizens and less time between line transfers. Yet its most outstanding plus, which makes it especially interesting, is its use as a "means of renovation in the city or area". In short, it is a project which impulses urban development in all senses of the word.

Nonetheless, it would seem clear the importance of acting on the existing bus network:
- Beforehand, in order to take advantage of the capacity that this modes of transport has as well as its efficiency;

- Once the light rail network is put into service, integrating both networks and remodelling the bus network so that this becomes a complement on the route and not competition.

Finally, the pros and cons of this system versus a conventional underground metro network are described in Table 1.

\subsection{Cost ranges for a Spanish Project}

The main findings from the first phase regarding cost issues are:

(1) investment: 10-15 $\mathrm{M} € / \mathrm{km}$ in comparison with 30-35 M€/km of conventional underground metro;

(2) development: $8 € / \mathrm{km}-9 € / \mathrm{km}$ (for bus routes $1.3-1.7 € / \mathrm{km}$ ) on out of town routes $3.5-4 € / \mathrm{km}$ on city routes). Rolling stock: $2.5 \mathrm{M€/unit;}$

(3) distribution between operation and maintenance: 55-60/45-40\%;

(4) start-up investment, the proportion with respect to the total is situated around:

- civil 55\%-65\%; 
- systems $15 \%-20 \%$;

- rolling stock: $20 \%-25 \%$.

\subsection{Barriers, Critical Aspects and Keys for Success}

About these three issues, with the interviews, very interesting lessons learnt can be highlight as follows.

A transport authority is an important element for agreements between Public Administrations and allows for questions to be answered such as who will pay? How will the financial responsibilities be divided both for investment and well as operation? It also facilitates the conciliation between technical criteria with the political ones.

A guaranteed minimum demand must exist from the beginning irrespective of what can be expected with future developments so that a concession can be put into service with private initiative.

As has already been mentioned, the LRT can be seen as a regeneration plan for the city so this can boost it towards success. There must be ambition implicit in the project (not only in terms of transport) coupled with financial realism.

Legal and financial problems have been easily resolved in Spain in recent years, though these factors could become critical within the framework of the current economic downturn.

Light rail projects are more complex, due to their immersion into the urban environment, than conventional underground metros and less flexible than the bus network (with this modes of transport, if a mistake is made in the design phase it is possible to remodel this as thesupport, the road has more branches).

They must be planned and co-ordinated with sufficient time so that they become "the project" and does not end up being a project with clearly-defined aims. "It is not good when we are dealing with a project merely linked to an electoral campaign, or a legislative period" as this is called in Spain.

A problem that light rail networks face is the construction phase, as this is truly conflictive due to the inconvenience caused to residents, and, above all, the businesses that see their level of trade notably reduced during some time.

It is very useful for the Public Administrations that is boosting the project to assume the leadership role in it, although always with wide-ranging agreements between all the competent bodies. This means, a Public Administration, or responsible body which is capable of pushing the project on without forgetting that this must be co-ordinated with the parties involved.

The implication of local companies, without this being compulsory, it usually of benefit as "they wish to remain and they want to fit in with the environment".

It is important to include bonus as well as penalizations in the contracts.

The composition of the partners in the tender group or consortium is debatable:

- The constructors tend to disappear during the operational phases (when the structure or the partnership is flexible) yet from then on they do not assume the same level of responsibility for faults which can occur;

- The operators are often absent in the structure during construction, yet, these are the ones who will occupy the space in the long term;

- Other agents are unsure if they should form part of the company structure or not: financers, consultancies, rolling stock manufacturers.

Signalling priority and a good commercial speed are key factors for the success of the projects as are the quality of service and on-board cancellation. Another critical issue is the decision to include underground sections or not.

In terms of design, an issue which is becoming of increasing importance is the catenary, due to the demands that these have a reduced visual impact, and in general, as a result of concern for urban aesthetics, as was mentioned at the beginning.

Communication and public engagement in all phases with the social stakeholders involved is another essential task to be included in the project development. 


\subsection{Financing and Management System.}

Regarding financing and management issues, it can be remarked as follows.

It is not clear whether the construction should be included in the concession bids, experts generally concur that, at the end of the day, this does not result in an earlier setup of the projects, and investment costs could go over-budget. This can only be justified if:

- There is a high opportunity cost, either because of public deficit or a lack of capacity to manage the project. On the other hand, as the social benefits are greater in relation to the investment, then the launch of the project must be brought forward as much as possible;

- The contract and legal framework allow for the adequate control of the concession and its costs.

In a period of between 20 and 25 years of concession is insufficient to cover investment, a residual value can be established for a transfer under the proper conditions though it is not advisable to lengthen the concession periods.

Under an operational tender, the timeframe must be of between 6 and 10 years. An intermediate alternative is the Porto formula which has a much reduced deadline towards being put into service in less time, to build capacity with and the lessons learnt by the Public Administration.

The DBOT (BOT including design) tenders (as established under Article 22 of the Spanish Tenders Law) can provide a solution worthy of contemplation in order to take advantage of the capacity of private initiative. Yet this opinion is not fully shared by many experts who tend to believe that the citizens' needs are better understood by the Public Administration. This is a system which was implanted by the Highways Agency in the United Kingdom, tackling aims such as:

- Minimising the contribution required and optimising the level of riskv [8] assumed by the public sector;

- Ensuring that the projected routes were designed, maintained and operated satisfactorily to maximise any adverse impact on the environment thus maximising the benefits felt by the users;

- Promoting innovation, not only in terms of technical and operational aspects, but also in terms of financial and commercial organisation;

- Fulfilling the government aim of encouraging the development of a private-sector for United Kingdom motorways.

All groups agree that the importance of effective operation for the success of the project, as the service is the final aim and its effect is that which will be felt for the entire life-cycle of the project.

Private operation can have three advantages, although they do not always give good results:

- Avoiding union interference;

- Optimising the experience of the private company when it is not present in the Public Administration;

- Reducing activities to those which are strictly necessary in order to avoid inefficient or excessive expenses, limiting political interference.

An integrator is necessary in the projects, the experts recommend an engineering firm or even a rolling stock manufacturer.

The Public Administration must be responsible at all times for the concession, supervising it and checking the contract is fulfilled.

The importance of financial advisors seems clear as they provide a good source of information on demand and costs.

The BOT Model has the advantage of simplicity and financial postponement, but the reality in Spain means that this is complex due to lack of transport bidders with clear interests in the business, coupled with the financial capacity to see this through. On the other hand, although it seems that these are going to change, the traditional contracting mechanisms do not work properly, they are rigid, enclosed and do not allow for fair renegotiation based on incomplete contracts with gross costs or similar formulae.

For example, the new Spanish concessions' law foresees competitive dialogue, via the method of 
incomplete contracts, though one must taken into account that this causes for "time to be spent in contract negotiations". Some experts contend that there must be the possibility of provisional pricing and a system of "cost-plus" which prevents wear and tear and over-costing during constructions as changes always occur. The presence of mediators, for example, would be a possible solution. An example of current trends in Spain can be seen with the Granada Metro, for which the Andalusian Railways Agency will invite tenders for and contract the project (up to five or six sub-contractors) and operation will be hired via another tender, perhaps using the "gross-cost with incentives" method. The rolling stock depends on what decisions are made regarding:

- transfer system;

- financial equity;

- contract length.

Though in the case of the company responsible for the Tenerife Metropolitan Railway, just 20\% was sufficient because the ticketing income is greater than $50 \%$ (commercial income) of the production costs, which is a necessary condition (not enough), to follow EU (European Union) rules for funding. The EU requires that the majority share of a mixed company (public and private sector) be private as to avoid being considered part of public deficit. That said, though in the case of the company responsible for the Tenerife Metropolitan Railway [9], just 20\% was sufficient because the ticketing income is greater than $50 \%$ (commercial income) of the production costs, which is a necessary condition (not enough), to follow EU rules for funding.

An interesting example is that of the last section of Line 8 of the Madrid Barajas Airport Metro. Investment and infrastructure management were private, but the transport service operator is from the public-sector. This means, investment does not figure in the public deficit, yet the control and quality standards of the operation are maintained.

The assessment of the British experience is interesting in so far as it considers what is known as "value for money", put more simply, profit returns on public money. When a PPP is undertaken in England, a "Public Sector Comparator" is carried out: How much would it cost if it were done publically or privately? To do this, an important database is required. A private-sector company, in theory, provides fewer delays, as it would be a turnkey project and delays mean reductions in income. This has been closely studied in the United Kingdom. The new Spanish Law for Public Service Contracts of 2007 has already contemplated this. Though one must take into account that the United Kingdom is not subject to SEC-95, (EU rule for public accountings). As well, in Spain, the aim is that the public accounts are not affected.

The opportunity cost of a BOT is based on the loss of social benefits due to the delay which could be produced in a project due to lack of public funds to finish it and because the repayment of the Public Administration's contributions are made via company $\operatorname{tax}$.

\subsection{The Process of Tender and Awarding}

Tender arrangements are considered by experts as a critical subject.

Unfeasible requirements must not be (excessively strict punctuality indicators for surface transport systems, for example).

Operational proposal must be properly evaluated.

Good base documentation is necessary, above all, in the planning stages.

Documents must be clear and detailed according to the majority of the experts, and the quality of the contracts is a key issue for the proper functioning of the project as mentioned in other studies, such as Roy Yvrande-Billion [10].

The progress clause considered in the Spanish legal framework (that requires that the concessionaire must adapt the system to the advances over the time period of the concessions is important although its application causes uncertainty. 
Bid evaluations may and must be carried out by specialists, who should even be independent. It is important to analyse every aspect of these bids to understand every minor detail.

It must be demanded that the offers contain the key aspects referred to in the awarding criteria in a clear and concise way in the conditions document in order to achieve an easier comparison of proposals. Aspects which would be considered of interest to include in this documentation are:

- Cost per $\mathrm{km}$ and cost per passenger valued at current prices and within different timeframes;

- Service offer (timetables, headways, etc.).

Owner recommendations from the expert to enrich future tenders are as following: Though the Public Administration must have an important negotiation capacity and this demands that the Public Administration's must be highly competent. If not, it is necessary to seek out an external consultant as is recommended in different multilateral guides for tender. This could be a freelancer or company with experience in the sector. This option could cost relatively little comparing to the investment. The need is for someone to identify where the potential problems are as following:

- In terms of the awareness barometers, these must be done in such a way that, for example, on a scale of 1 to 10 , all these items score at least 7 , as, for example, the compensatory aspects of the practices in force at the moment mean that an unbalanced proposal with good and bad aspects can win. This should not be the case;

- The financial element is not only the economic value of the construction and/or the operation of the line, rather the delivery conditions and risks. This is more difficult to measure though very important. Therefore, the financial aspect is of great importance yet, all of its facets must be taken into account. Looking at the Seville Metro [11] case where the winning bidder was the one which offered a lower investment cost, around $30 \%$ less, and the true cost has practically doubled, this shows that giving the contract to the cheapest brings with it an important risk as the project was not as well defined as with other bids.

\section{Phase II-Results Tabulation}

With regards to the results obtained from the previous phase, seven essential points were established for which a system of parameters depending on fixed limits. The issues approached were as follows.

\subsection{What Is the Minimum Daily Demand Level Which Would Justify a LRT?}

As can be seen in Fig. 3, the majority of the experts consider that a daily demand level of 20,000 passengers is sufficient, and this coincides with the idea expressed in the interviews that light rail networks

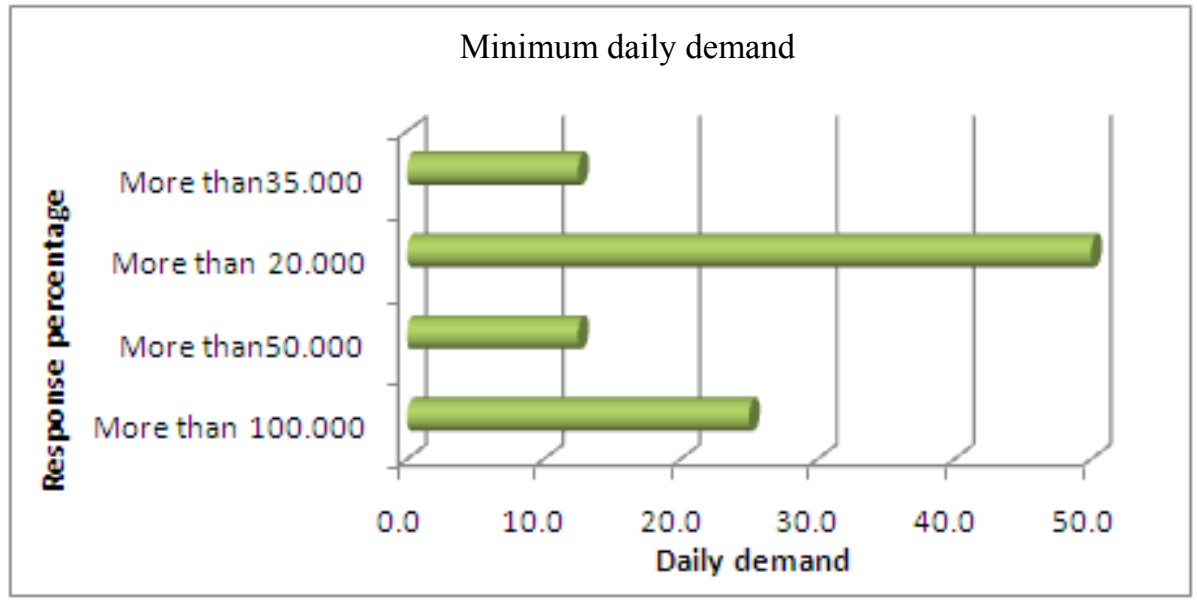

Fig. 3 Minimum daily demand level.

Source: In-house based on Delphi survey. 
are largely a city project and not exclusively a way of tackling a mobility issue. These levels of passengers could be handled by the use of bus routes on reserved platforms [12], however, many experts consider that it is an opportunity to act in the city and carry out a significant project such as a tramway or light rail network.

\subsection{Which Type of Partners Are More Important in a BOT?}

In most cases, the experts consider that the operators are key and essential partners, something which contrasts with the current situation in Spain. Consultancies, as can be seen in Fig. 4, do not seem to have as an important role in the concessions from engineering agencies as the partners, despite the analysed tendency for their participation with reduced percentages, as can be appreciated in Table 2.

\subsection{Which Financing and Management Model Do You} Recommend in General for the Development of a Light Rail Network?

The experts, according to Fig. 5, are divided between two main and extreme options:

- DBOT, in the opinion of some experts allows for the private-sector company to be able to contribute from the initial stages, as well as ensuring a certain level of efficiency whilst work is being carried out;

- Public construction via independent contract and operational concession, which is the solution seen to be most efficient in financial terms for recently completed projects in Spain.

4.4 What Motives Do You Consider Can Justify Private-Sector Participation in a Light Rail Network Project?

Once again the experts are divided between the diverse possibilities, all the factors suggested in the questionnaire have been evaluated, as can be seen in Fig. 6. This means that there are many reasons worthy of consideration which put forward the idea of private-sector participation, as were singled out in Ref. [13]. On the other hand, the creation of a powerful industry which can compete in the worldwide market [5] is considered interesting but secondary.

\subsection{Who Should Carry out the Construction Project in a LRT Project?}

Expert opinions indicate that, if we look at Fig. 7, there is a division between those who believe that the

\section{Types of BOT patners}

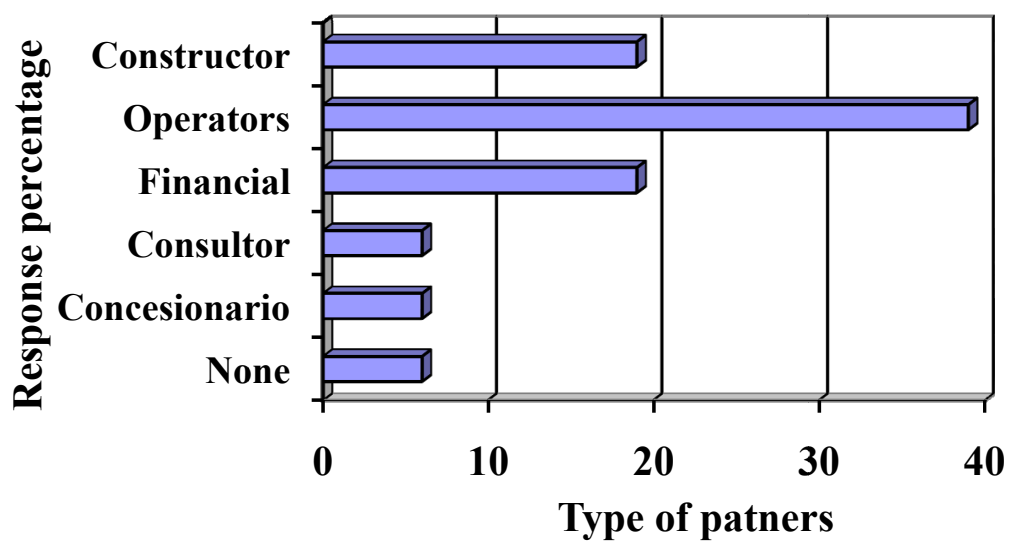

Fig. 4 Types of partners in a BOT.

Source: In-house. 
Table 2 Functions of the different agents.

\begin{tabular}{|c|c|}
\hline \multicolumn{2}{|c|}{$\begin{array}{l}\text { Functions of the different agents who normally form part of a bidding company for the construction and development of an urban } \\
\text { transport system }\end{array}$} \\
\hline Participants & Role \\
\hline Constructor groups & $\begin{array}{l}\text { Partner in the concessionare generally with leadership through a bidding company of the Constructor Group } \\
\text { Construction and even installations }\end{array}$ \\
\hline $\begin{array}{l}\text { Rolling stock } \\
\text { manufacturers }\end{array}$ & $\begin{array}{l}\text { If they are partners, supply of the rolling stock and responsibility for its implementation } \\
\text { Suppliers, being able to form part of the supply group of the concessionare with the constructor }\end{array}$ \\
\hline Operators & $\begin{array}{l}\text { Their presence as a partner is not common in Spain, though guarantees experience and long-term implication } \\
\text { Constructor groups power make them seem like subcontractors in Spain } \\
\text { They represent the final aim of the process, the fulfilment of a service }\end{array}$ \\
\hline Financers and banks & $\begin{array}{l}\text { They provide capital and financial guarantees } \\
\text { They often have little involvement in the creative process and business design } \\
\text { They can participate just as advisors for the financing design }\end{array}$ \\
\hline & $\begin{array}{l}\text { These can work for the: } \\
\text { Winning bidder; } \\
\text { Builders' Consortium; } \\
\text { The Public Administration. }\end{array}$ \\
\hline Consultancies & $\begin{array}{l}\text { They can participate in the: } \\
\text { Bid; } \\
\text { Project; } \\
\text { Project Management: quality control; } \\
\text { Operation assessment; } \\
\text { Systems integrator. } \\
\text { Their role is still subject to great debate, and in any case, it is often with a reduced percentage which ensures } \\
\text { their continuity in the process and shares out the financial burden between the various parties which can } \\
\text { reduce the cost of financing. }\end{array}$ \\
\hline
\end{tabular}

Source: In-house based on Delphi survey.

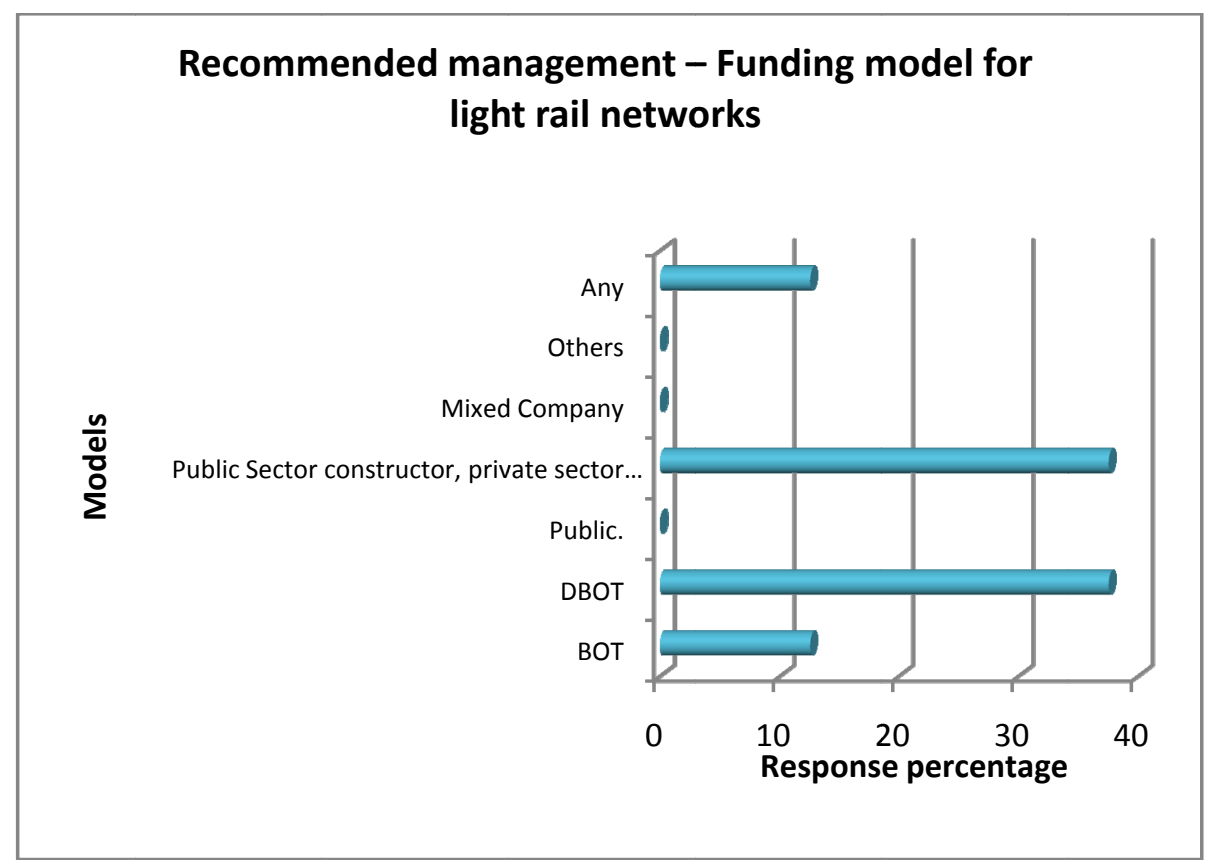

Fig. 5 Recommendable financing and management models for a light rail network.

Source: In-house based on Delphi survey.

construction project should be carried out by the Public Administration, and those who think that the successful bidder should do this so that it is they who assume all the construction risks. This vision concurs with the answer given for question $\mathrm{C}$ regarding the most adequate model. 


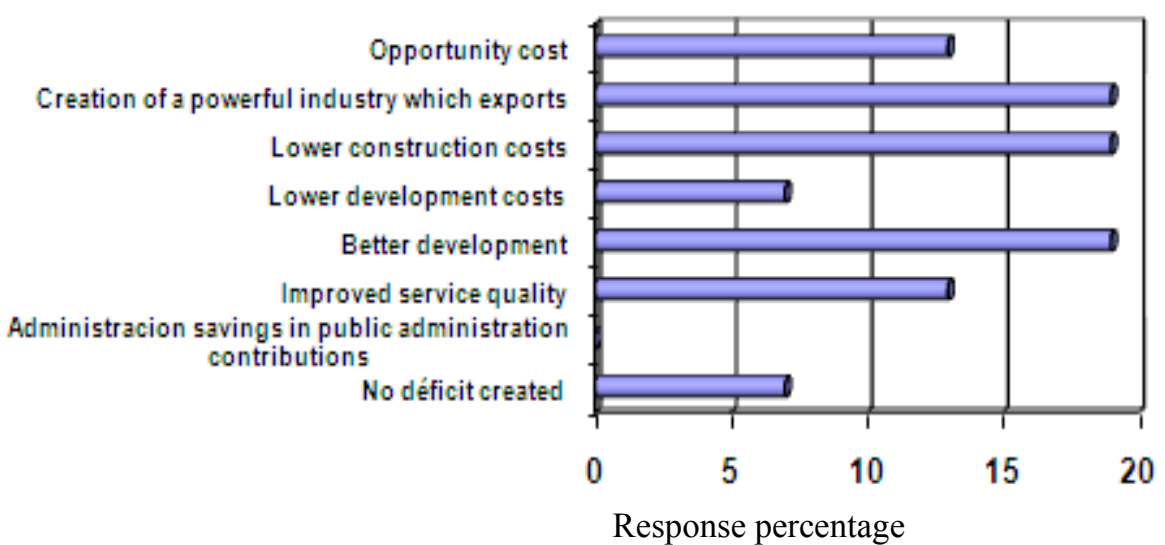

Fig. 6 Private-sector participation motives.

Source: In-house based on Delphi survey.

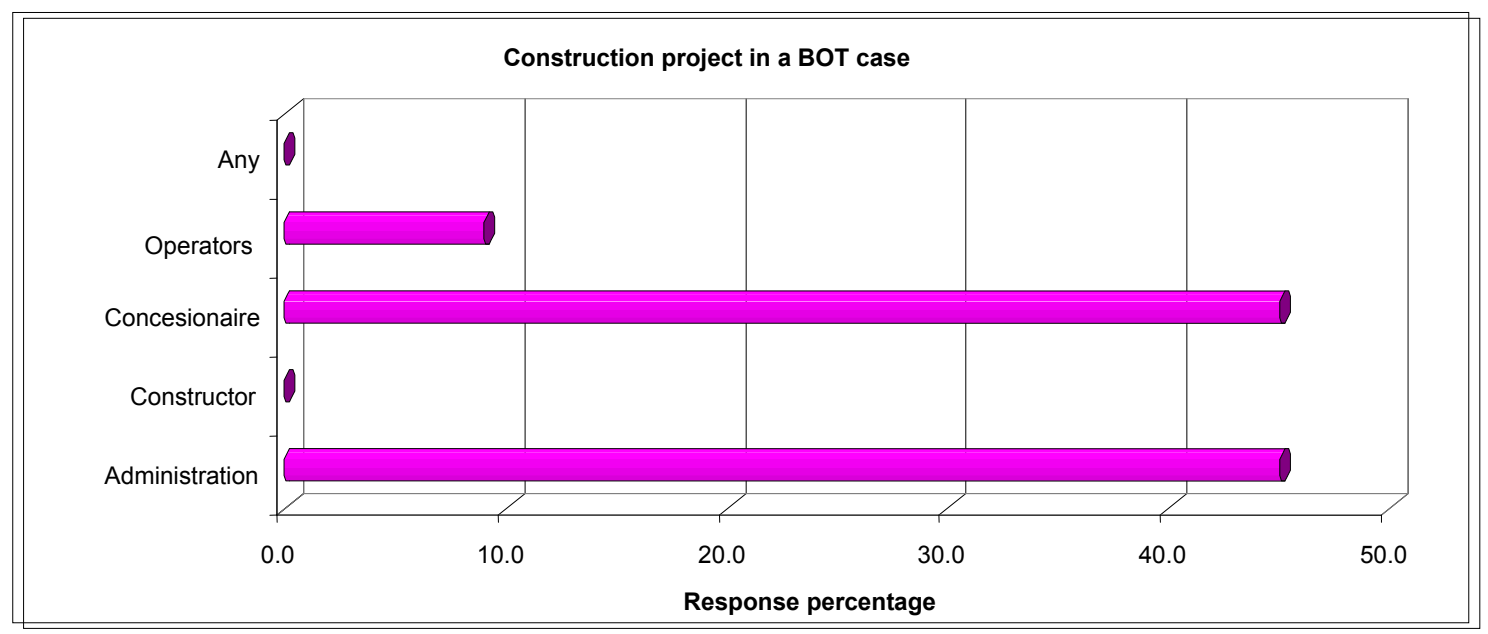

Fig. 7 Construction project in a BOT case.

Source: In-house based on Delphi survey.

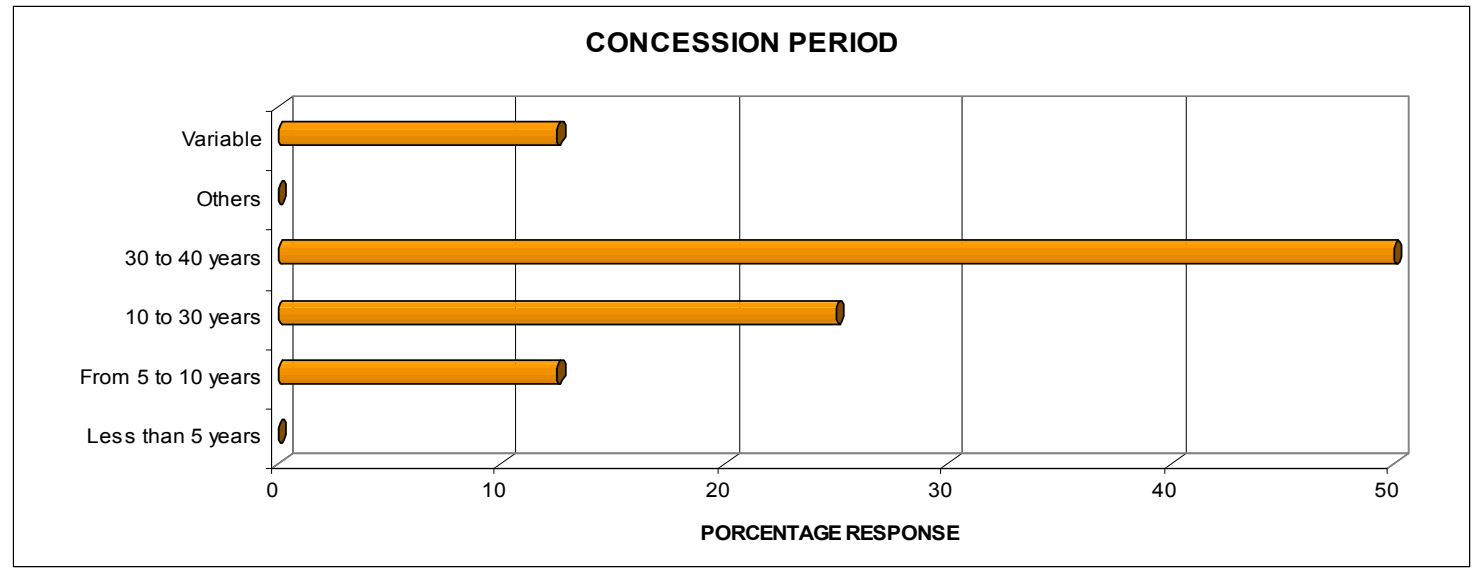

Fig. 8 Concession period.

Source: In-house based on Delphi survey. 


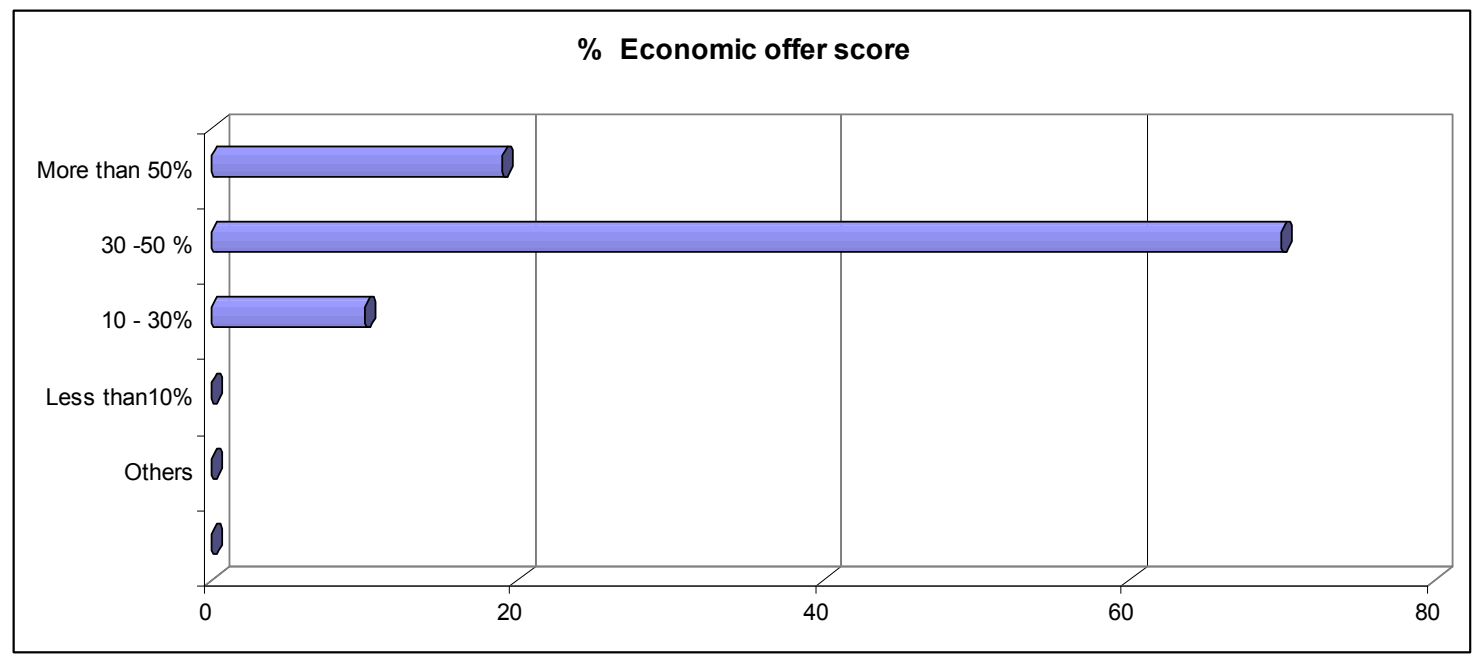

Fig. 9 Economic offer score.

Source: In-house based on Delphi survey.

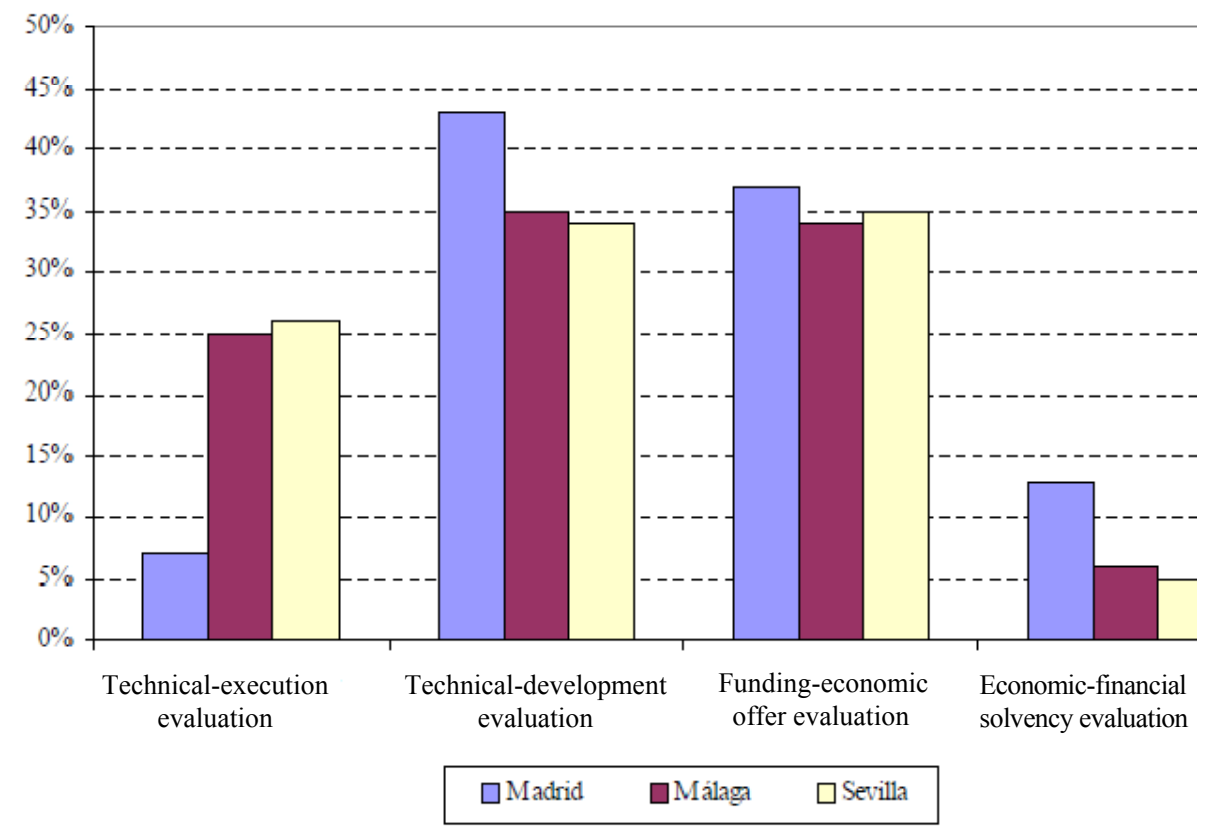

Fig. 10 Bidding evaluation.

\subsection{What Tender Timeframe Do You Consider} Generally Appropriate?

The majority, as can be seen in Fig. 8, choose a longer timeframe, like those used in Spanish projects, of between 30 and 40 years, which use up the maximum amount of time permitted by the 2003 Tenders Law. Shorter timeframes and variable timeframes are not highly regarded mainly when construction investment is included in the tender.
4.7 What Percentage Score Should the Economic Criteria Must Have in a Tender?

In their majority, the experts, as we can observe in Fig. 9, consider that this must not exceed $50 \%$ though that this must have a notable importance, around $30 \%-50 \%$ generally. The current terms of reference fulfil this criteria suggested by the expert panel (Fig. 10). 


\section{Conclusions}

In short, the analysis of the answers provided by the expert panel allows us to affirm that:

- The light rail networks can have a major impact if they are developed as city projects;

- The involvement of private-sector companies can provide expertise to the projects and allow for an earlier opening of the service, yet it is necessary to prepare this carefully and foresee adequate monitoring in all observational phases of the project;

- The development of light rail network projects based on construction via public budgets and operational tenders is an option which could integrate the advantages of the different models and allow for the versatility necessary in many cities, as long as the ruling Public Administration has the funds required to do this.

\section{Acknowledgments}

The authors are grateful for the funding provided by the Madrid Regional Transport Consortium (PTA of Madrid) to carry out this wide-ranging research project, focusing on the analysis of the relationship between private financing and type of project. We would especially like to express our appreciation to Jesús Rodríguez Molina and José Manuel Pradillo, Technical Director and General Manager of the Madrid Regional Transport Consortium.

\section{References}

[1] Manual for Planning, Financing and Implementation of Urban and Metropolitan Public Transport Systems, Madrid Transport Consortium, June 2004.

[2] J. Sastre González, Light rail network concessions: Public and private-sector participation, comparison of management and financing models, Doctoral Thesis, Universidad Politécnica de Madrid, 2009.
[3] Conditions Documents for the Parla Tranway Tender, Madrid Regional Transport Consortium, 2005.

[4] Conditions Documentation for the Contract Reduction of the Project, Construction and Development of the New Rail Line between Mostoles Central and Navalcarnero, Ente Público de Derecho Público, Infraestructuras del Transporte, Madrid, 2007.

[5] A. López del Corral, A. Sánchez Soliño, Economic analysis of the reform of the tender system for public works, Revista de Obras Públicas 149 (3425) (2002) 45-51.

[6] K.C. Green, J.S. Armstrong, A. Graefe, Methods to elicit forecasts from groups Delphi and prediction markets compared, Foresight: The International Journal of Applied Forecasting 8 (2007) 17-20.

[7] Manual for Tramways, Light Railways and Reserved Platforms: Design, Project, Financing and Implementation, Madrid Transport Consortium, 2006, p. 279.

[8] J.E. Schaufelberger, I. Wipadapisut, Alternate financing strategies for build-operate-transfer projects, Journal of Construction Engineering and Management 129 (2003) (2) 205-213.

[9] Conditions Documents Which Must Be Adhered to during Tenders for the Selection of Light Rail Network Operators Participating in the Equity of Tenerife Metro Public Company Ltd., Cabildo de Tenerife, 2002.

[10] W. Roy, A. Yvrande-Billion, Ownership, contractual practices and technical efficiency: The case of urban public transport in France, Journal of Transport Economics and Policy 41 (2) (2007) 257-282.

[11] Documentation for the Tender Conditions for Bidders on the Construction and Development of the Inter-Urban Line 1 Seville Metro in Which Services beyond the Scope of the Project and the Acquisition of Rolling Stock Are Included, Ministry of Public Works and Transport, Andalusian Government, 2001.

[12] Documentation for the Tender Conditions for Bidders on the Construction and Development of the Inter-Urban Lines 1 and 2 of the Malaga Metro in Which Services beyond the Scope of the Project and the Acquisition of Rolling Stock Are Included, Ministry of Public Works and Transport, Andalusian Government, 2003.

[13] C. Clements, M. O'Mahony, Traditional or public private partnerships for procurement of light rail transit?, in: TRB Annual Meeting, Washington, DC, 2004. 